\title{
INVESTIGACIONES
}

\section{Re-producción de fronteras en el espacio escolar. Discursos y prácticas de distinción nacional(ista) en escuelas con alumnado migrante en la Región Metropolitana de Chile}

\author{
Re-production of borders in the schools space. \\ Discourses and practices of national(ist) distinction in schools \\ with migrant students in the Metropolitan Region of Chile
}

\author{
María Fernanda Stang Alva ${ }^{a}$, Pablo Ignacio Roessler Vergara ${ }^{b}$ \\ Andrea Riedemann Fuentes ${ }^{c}$ \\ ${ }^{a}$ Centro de Investigación en Ciencias Sociales y Juventud. \\ Universidad Católica Silva Henríquez (CISJU-UCSH). \\ fstang@ucsh.cl \\ ${ }^{b}$ Fundación Servicio Jesuita a Migrantes. \\ pablo.roessler@sjmchile.org \\ ${ }^{c}$ Centro de Estudios Interculturales e Indígenas. \\ Universidad Católica de Chile. \\ andreariedemann@gmail.com
}

\section{RESUMEN}

Este artículo se propone reflexionar, a partir de los resultados de dos estudios realizados en establecimientos educativos con presencia de estudiantes migrantes en comunas de la Región Metropolitana de Chile, la forma en que discursos y prácticas construidas en torno a la nación y lo nacional producen y re-producen fronteras dentro del espacio escolar, incluso a pesar de que se propongan abordar algunos de los efectos de las clasificaciones y jerarquías que esas fronteras instituyen. El texto busca mostrar mecanismos concretos de estos procesos de fronterización, construidos desde la forma en que se dice y se actúa la nación.

Palabras claves: Migración internacional, Estado-nación, colonialismo, escuela, procesos de fronterización.

\section{ABSTRACT}

This article intends to reflect, based on the results of two studies carried out in schools with migrant students in communes of the Metropolitan Region of Chile, the way in which discourses and practices built around the nation and national issues produce and re-produce boundaries within the school space, even though they intend to address some of the effects of the classifications and hierarchies that these borders establish. The text seeks to show concrete mechanisms of these bordering processes, built from the ways in which the nation is said and acted.

Keywords: International migration, nation-state, colonialism, school, bordering processes. 


\section{INTRODUCCIÓN}

Existe cierto consenso que en América Latina más que en otras regiones del mundo, los Estados jugaron un rol muy importante en la construcción de las "respectivas" naciones (Cid, 2012). En efecto, en muchos países latinoamericanos las elites llevaron a cabo, mediante diversos mecanismos, un proceso que buscó naturalizar la construcción de una “etnia nacional" que pretendió desconocer la existencia de múltiples etnias, pueblos y naciones en sus territorios.

A su vez, el pasado colonial común de nuestros países llevó a que, en tales procesos, estas elites pusieran mucho énfasis en las diferencias respecto de los otros países de la región, una diferenciación que fue funcional a este imaginario de una identidad propia, única, y a la idea de que con la Independencia se establecía un hito fundacional respecto del tiempo colonial, aunque perdurara en la base de estas nuevas sociedades nacionales su estructura jerárquica sustentada en criterios étnico-raciales.

En Chile, la construcción de la nación fue también un proceso fuertemente guiado por el Estado y las elites (Bengoa, 2003), que mediante diferentes dispositivos buscaron instituir la idea de una nación homogénea, de gran influencia europea, de poca influencia indígena y casi nula africana, lo que condujo a un ensalzamiento de lo blanco-europeo y a un fuerte desprecio por lo indígena y lo afrodescendiente, representado como el epítome de la alteridad nacional.

Desde la primera mitad del siglo XIX el sistema educativo ha jugado un rol importante en ese proceso de construcción nacional (Egaña, 2000), encarnando en sus actores, a partir de una repetición cotidiana y ritualizada, las imágenes, ideas y acciones que performatizan esta "nación chilena".

Es desde la consideración de estos antecedentes que resultan comprensibles los discursos y prácticas que han surgido en muchas escuelas públicas del país que han estado recibiendo a los estudiantes migrantes que han llegado a Chile en los últimos años, en un contexto de crecimiento significativo de la migración de origen latinoamericano que ha transformado a un país eminentemente receptor en un destino relevante de las migraciones intrarregionales (Tijoux, 2013; Riedemann, 2017; Roessler, 2018).

En ese marco, este artículo se propone reflexionar, al hilo de los resultados de dos estudios realizados en establecimientos educativos con presencia de estudiantes migrantes en comunas de la Región Metropolitana de Chile, la forma en que discursos y prácticas construidas en torno a la nación y lo nacional producen y re-producen fronteras dentro del espacio escolar, incluso a pesar de que se propongan abordar algunos de los efectos de las clasificaciones y jerarquías que esas fronteras instituyen. El texto busca mostrar mecanismos concretos de estos procesos de fronterización, construidos desde la forma en que se dice y se actúa la nación.

\section{NACIÓN, FRONTERA Y ESCUELA: EL MARCO PARA NUESTRO ANÁLISIS}

En América Latina, los procesos de construcción de los Estados nacionales ocurrieron sobre un telón de fondo signado por las huellas profundas de un pasado colonial. Por esa razón, colonialismo y nacionalismo han sido $^{1}$ dos importantes fuentes para la constitución

Si bien en términos políticos el régimen colonial es parte del pasado, reconocemos que en términos socioculturales, las huellas del colonialismo siguen vigentes. Al respecto, ver por ejemplo el libro Violencias coloniales en Wajmapu, editado por la Comunidad de Historia Mapuche (2015). 
de identidades y alteridades en nuestros países, y en Chile en particular, forjando "un poderoso imaginario nacional que legitima la subordinación y la hegemonía" de unos sobre otros (Tijoux y Córdova, 2015, p. 8), donde han jugado un rol relevante criterios étnicos y "raciales". En efecto, los procesos de diferenciación (o de fronterización) social en las formaciones sociales latinoamericanas se construyen "dentro de una estructura y matriz colonial de poder racializado y jerarquizado, con los blancos y 'blanqueados' en la cima y los pueblos indígenas y afrodescendientes en los peldaños inferiores” (Walsh, 2003, p. 4). Asumir y problematizar la existencia de esta matriz para pensar los procesos sociales que nos ocupan en este trabajo resulta central para entender la manera en que trazamos los límites entre "nosotros" y "los otros" (Todorov, 2010), o sobre lo que definimos como parte de la nación y qué no (Segato, 2007).

Es decir, esa específica y estrecha relación entre la matriz colonial y la estatal-nacional ha sido, y continúa siendo, un decisivo mecanismo de trazado de fronteras sociales en nuestros países. Cuando decimos matriz estatal-nacional, además, buscamos poner en evidencia otro aspecto relevante de estos procesos: la operación que pretendió ligar, de manera unívoca, la institución jurídico-política del Estado a la nación, que se buscó a su vez instituir mediante diversas tácticas y estrategias, muchas de ellas sustentadas en violencias materiales y simbólicas. Es allí donde reside una de las especificidades latinoamericanas en este ámbito, puesto que también a escala global:

el nacionalismo [fue] el proyecto para hacer que la unidad política, el estado... fuera congruente con la unidad cultural, la nación. (...) El nacionalismo se ha examinado como una ideología política que sostiene que cada estado debe tener su nación y cada nación su estado (Fox y Miller-Idriss, 2008, p. 536, traducción propia)².

Pero en América Latina, este proceso tiene a su vez una compleja relación con la dimensión étnica, pues como observa Domenech (2003) a partir de los análisis de Bauman (2001) y Balibar (1991), en nuestra región, a diferencia del resto de occidente,

las elites se enfrentaron a la doble tarea de 'dar una nación a la etnia y al mismo tiempo dar una etnia a la nación’ (Bauman, 2001: 47) (...). Según Étienne Balibar, ‘ninguna nación posee naturalmente una base étnica, pero a medida que las formaciones sociales se nacionalizan, las poblaciones que contienen se reparten o dominan, dichas formaciones son 'etnicizadas', es decir, representadas en el pasado o en el futuro como si constituyeran una comunidad natural, dotada por sí misma de una identidad de origen, de cultura y de intereses que trascienden a los individuos y las condiciones sociales (Balibar, 1991, en Domenech, 2003, p. 37).

Es por eso que insistimos en la articulación de colonialismo y nacionalismo para analizar procesos sociales como los que se tematizan en este trabajo. Y también es por eso que, como señalaremos hacia el final de este artículo, la perspectiva de la interculturalidad crítica (Walsh, 2003; 2009; 2012) nos parece la más idónea para los desafíos que están enfrentando las instituciones educativas sobre las que hemos investigado.

En el original: "[n]ationalism is the project to make the political unit, the state (or polity) congruent with the cultural unit, the nation. (...) Nationalism has been examined as a political ideology holding that each state should have its nation and each nation its state". 
La escuela ha sido un escenario muy relevante para la construcción del Estado-nación, por lo que no son casuales los discursos y prácticas sustentados en la idea de nación -o, mejor dicho, en una idea de la nación- que han emergido en las escuelas del país ante el incremento y la diversificación de la matrícula de estudiantes migrantes que se ha observado en los últimos años, principalmente en algunas regiones, y en ciertas comunas de Chile ${ }^{3}$.

Este punto de partida, que explicita las principales ideas-fuerza que sustentan el análisis que se presenta en este artículo -a saber, nación y frontera, abordadas específicamente desde su relación en y con la escuela-, remite a un modo de entender la nación como "una compleja construcción política, social, cultural, simbólica, discursiva y aún estética, en constante transformación y replanteamiento a través del tiempo" (Cid, 2012, p. 332).

La frontera, a su vez, comprendida evidentemente de un modo que excede la asociación con los límites geopolíticos de los Estados, y que tampoco se limita a un anclaje espacial, representa un elemento decisivo en este proceso de construcción de la nación. Procurando despojar esta noción de su habitual carácter topográfico, la frontera es entendida en este artículo -realizando una apropiación sui generis de la propuesta de Stefoni et al. (2018)-, como un proceso mediante el cual el Estado-nación actúa "estructuralmente (construyendo legitimidades y regímenes de adscripción de las gentes), mientras la agencia de sujetos diversos resignifica y negocia las clasificaciones nacionales" (2018, p. 12). Desde ese entendido, en el análisis que proponemos se articula una mirada de la actuación estructural del Estado, y específicamente desde la institución de la escuela, para construir estas adscripciones identitarias (y como correlato, las exclusiones que ellas suponen), con la forma en que esta actuación se materializa en discursos y prácticas concretas, en las que los sujetos reproducen, y re-producen, esas adscripciones/ fronterizaciones.

La distinción entre reproducción y re-producción no es simplemente un juego de palabras. Como sostiene Hobsbawm (1990), la nacionalidad debe investigarse también "desde abajo", y no solo desde los mecanismos oficiales: ni la población en general, ni los alumnos que asisten a las escuelas, son "recipientes vacíos" de los proyectos nacionales que vienen desde el Estado. Es importante entonces considerar a los actores involucrados en estos procesos de socialización cotidiana, alejándose de perspectivas verticalistas de transmisión identitaria (Skey, 2009). No solo el Estado define la nacionalidad, sino que las personas, en cuanto actores, también lo hacen desde su habla y sus actos cotidianos. En palabras de Fox y Miller-Idriss (2008), la nación se habla y actúa o, en otros términos, existe una performatividad en la construcción de la nación. Siguiendo a estos autores, la nación puede indagarse entonces tanto en el habla (¿qué es la nación?) como en las prácticas cotidianas (¿cuándo es la nación?). Desde estos aportes, entendemos que las identidades nacionales, junto con ser un proyecto estatal hegemónico con claras intenciones políticas, son también una construcción y recreación constante, actuada por las personas en la vida cotidiana, y jamás algo estable y coherente en el tiempo ni en el espacio (Skey, 2009). Si bien construir nación fue y es un objetivo primordial del Estado, no se debe omitir la negociación social que esa tarea ha generado (Cid, 2012; Fox \& Miller-Idriss, 2008).

Existe un amplio consenso acerca de que la institución de la escuela ha cumplido un rol central en la producción y reproducción de una idea particular de identidad nacional

En 2017 los estudiantes extranjeros representaban el 2,2\% de la matrícula nacional (Fernández, 2018) y en el año 2018 esa cifra llegó al 3,2\% (siguiendo datos del SIGE, 2018), pero lo relevante en este punto es que en algunas escuelas de ciertas comunas de la Región Metropolitana en las que se concentra la población migrante internacional, ese valor puede rondar en torno al $50 \%$. 
(Giroux, 2011; Bourdieu \& Passeron, 1996). El Estado, por medio de dispositivos institucionales como el sistema educativo nacional, ha buscado hacer converger a las personas dentro de un proyecto de pertenencia cultural llamado nación (Connor, 1978). En América Latina, "nacionalizar" ha significado el deseo político de homogeneizar, y el anverso de ese deseo ha sido la invisibilización de las particularidades culturales que componen un territorio, fundiéndolas, traduciéndolas como agentes folclóricos que hicieron posible el presente, pero que se diluyen y se tornan en alteridades inferiorizadas (Bengoa, 2003; Diez, 2004; Segato, 2007; Tijoux, 2013). En palabras de Díaz y Druker (2007), la escuela sigue siendo un aparato normalizador y creador de identidades uniformes, que busca socializar a los niños y adolescentes dentro de un imaginario nacional homogéneo, y aun reconociendo que existen tensiones y resistencias a esta acción homogeneizadora, es preciso admitir el éxito que ha tenido esta estrategia hasta la actualidad.

También en Chile la educación ha sido explícitamente pensada, desde la intelectualidad y la dirigencia estatal, como plataforma de construcción de una identidad común para todos sus habitantes y, junto con esto, de legitimación política (Cid, 2012). Para la elite chilena al momento de institución del Estado-nación, la generación de un relato sobre un origen común, que ligara las tradiciones del pasado prehispánico, la colonia y la República, fue una tarea fundamental ${ }^{4}$. Este proceso se aceleró además durante la segunda mitad del siglo XIX, cuando en una reconfigurada realidad territorial del Estado, luego de la Guerra del Pacífico, se hizo de la escuela "una herramienta crucial para culturizar en clave nacional a poblaciones pluriétnicas que no estaban en los límites originales del Estado chileno decimonónico" (Cid, 2012, p. 333), tanto hacia el norte como hacia el sur, en lo que este autor denomina una "chilenización por las aulas". Esta expansión territorial, que explica también la importancia que se le ha dado después a la construcción de un imaginario espacial del Estado-nación, coincidió entonces con reformas educativas llevadas adelante en la década de 1880, que apuntaron a fomentar la educación cívica y la difusión de valores patrióticos (Rojas Flores, 2004). Por otra parte, en 1920 entró en vigencia la ley de educación primaria obligatoria, medida por la cual aquellos grupos que hasta esa fecha habían optado por no enviar a sus hijos e hijas a la escuela tuvieron que comenzar a hacerlo -entre ellos, los mapuche y otros pueblos indígenas que, por la expansión territorial, pasaron a formar parte, al menos formalmente, de la "nación chilena"s_.

En este marco histórico, se pusieron en marcha diversas estrategias que, en muchos casos, continúan operando hasta la actualidad:

maestros que sólo hablaran castellano en escuelas con presencia de niños indígenas, imitación de modelos europeos, entrega de contenidos que no guardaban relación con las particularidades del contexto o las culturas locales y una oferta curricular homogénea (Poblete y Galaz, 2007).

"Origen de la identidad chilena", [en línea], http://www.patrimoniocultural.gob.cl/614/w3-article-53539.html?_ noredirect=1, consultado el 20/02/2019.

5 A modo de paréntesis, en este punto es relevante comentar que el fenómeno migratorio que Chile experimenta desde la década de 1990 no representa, en la historia de la educación chilena, el primer hecho que enfrenta a su sistema educativo con la diversidad cultural. El primer encuentro de culturas considerablemente diferentes dentro de la escuela chilena se produjo justamente tras la entrada en vigencia de la mencionada ley. Para los pueblos indígenas esta norma significó una sistemática denostación de prácticamente todos los aspectos de sus culturas, incluido su modo de vida, su cosmovisión, su manera de transmitir conocimientos a las nuevas generaciones, sus lenguas, etc. (Donoso, 2008). 
El proceso de chilenización, por otra parte, le otorgó un papel muy significativo a ciertos elementos en particular: la bandera, como tótem moderno; el himno, como herramienta de difusión/construcción de la identidad nacional en una cultura oral como la decimonónica; la guerra, como recurso definitorio del temple nacional (Cid, 2012), recursos que encontraron continuidad y nueva energía más adelante, durante la dictadura cívico militar comandada por el General Pinochet, mediante un discurso castrense enunciado además desde el lugar usurpado de mandatario, que siguió contribuyendo a la construcción de una nación imaginada como un pueblo homogéneo y unitario (Cuevas, 2014).

El refuerzo de la observancia de los emblemas y símbolos patrios fue un objetivo explícito del sistema educativo chileno durante las primeras décadas del siglo XX, en el preludio de la celebración del centenario del país, y con posterioridad a ella, una directriz que se mantuvo a lo largo de esa centuria ${ }^{6}$. Estos procesos, como hemos ido señalando, son comunes a muchos de los países latinoamericanos, aunque por supuesto con especificidades nacionales? ${ }^{7}$.

Visibilizar y problematizar estos marcos nacionalistas y colonialistas aún vigentes en nuestras sociedades y, por ende, en nuestras escuelas, hace posible cuestionar fenómenos naturalizados (Walsh, 2012), como los que están en la base de la manera en que son percibidos los estudiantes migrantes por las comunidades educativas en la actualidad, o en las decisiones que se toman para abordar los desafíos que su presencia representa para las escuelas. Los niños y adolescentes migrantes son concebidos como portadores cotidianos de la frontera (Ramírez y Álvarez, 2009; Vigh, 2009), y como sujetos desterritorializados que rompen ciertos isomorfismos o mimetizaciones entre la persona y la nación. Son observados como outsiders del Estado, como una excepción anómala a la regla de sedentarismo, y como "otros culturales", que se perciben aún como manchas en el "color puro" de la nación, y que debiesen ser absorbidos, según las representaciones y prácticas más generalizadas, por medio de políticas de asimilación forzada o de integración benevolente (Wimmer y Glick Schiller, 2002).

En los próximos apartados, presentaremos discursos y prácticas concretas sobre cómo funcionan estos procesos de fronterización derivados de la articulación de la matriz colonial y estatal-nacional en algunas escuelas chilenas que han estado recibiendo estudiantes migrantes en los últimos años. El primer apartado, centrado en los discursos, se basa en la mirada de los estudiantes chilenos; el apartado siguiente, enfocado en las prácticas, en la óptica de directivos y docentes.

“Cómo se enseñaba Historia y Educación Cívica en Chile (1910- 1930)", [en línea], http://www.museodelaeducacion.gob. cl/648/w3-article-25823.html?_noredirect=1, consultado el 20/02/2019.

7 En ese sentido, resulta interesante observar lo que ocurría en el sistema educativo argentino en las décadas previas a su propio centenario, signado por la reacción del Estado frente a la "amenaza" que experimentó con la llegada masiva de migración europea promovida por el gobierno: "La respuesta a esta preocupación [por la transformación social generada por esta población migrante], que surgió en distintos grupos de la élite dirigente y movilizó luego a sectores más amplios de la sociedad, maduró a medida que se desarrollaban los conflictos (...) La respuesta se encontró en la nacionalidad, que se consideró no solo un aglutinante social para contrarrestar la disgregación interna, sino un pilar en el cual afirmar la plena soberanía de la nación frente a una situación externa amenazante. Desde la segunda mitad de la década del ochenta [1880] se advierte la puesta en marcha de un emprendimiento... para la 'encarnación' de la nacionalidad, respaldada en la tradición patria, que tuvo en la escuela y en la celebración de las fiestas patrias sus instrumentos decisivos" (Bertoni, 1992, p. 79-80). 


\section{FRONTERAS COTIDIANAS DE DISTINCIÓN NACIONAL: TERRITORIO Y TRADICIONES COMO MARCAS DE IDENTIDAD EN EL DISCURSO DE LOS ESTUDIANTES CHILENOS}

En este primer apartado se describen algunos resultados emergentes de una investigación ${ }^{8}$ que buscó comprender cómo los adolescentes chilenos que conviven con pares migrantes en el espacio escolar construyen y se apropian de elementos referentes a lo que entienden por identidad(es) nacional(es) chilena(s). Este estudio siguió una metodología de carácter cualitativo, a partir de la realización de grupos focales (6) y entrevistas individuales (18) a adolescentes chilenos $/ \mathrm{as}^{9}$ que tuvieran contacto con estudiantes migrantes en el espacio escolar $^{10}$. El trabajo de campo se desarrolló en 2016 en seis establecimientos educacionales municipales de las comunas de Santiago y Quinta Normal, de la Región Metropolitana: los tres de Santiago presentaban un mayor porcentaje de matrícula migrante (sobre un 14\% de su matrícula total), y los tres de Quinta Normal un porcentaje menor, pero creciente ${ }^{11}$.

Como resultado general, se identificaron discursos de los adolescentes nativos sobre su identidad nacional que establecen fronteras entre un yo-chileno y un otro-inmigrante. Mediante elementos determinados de distinción nacional -producidos, reproducidos y re-producidos en sus discursos- estos estudiantes chilenos posicionan a sus pares de origen migrante como portadores cotidianos de fronteras que delimitan, a partir de ciertos marcadores identitarios, los atributos que permiten distinguir entre nosotros y los otros.

A través del análisis emergieron primordialmente tres tipos ${ }^{12}$ de fronteras cotidianas, asociadas a 1) un uso particular del español en los chilenos, 2) una posesión también particular de aspectos físicos o raciales ${ }^{13}$, y 3) una pertenencia espacial con el "territorio chileno". A continuación, nos detendremos específicamente en el análisis del tercer elemento, retomando algunos resultados descritos en un trabajo anterior (Roessler, 2018) -que muestran cómo el discurso de estos adolescentes traza una frontera definida por el nacer-permanecer en un territorio determinado-, y aportando resultados nuevos acerca de cómo la pertenencia a este territorio se liga a ciertas costumbres y tradiciones. Como se verá, entre ellas resultan muy significativas - por la insistencia de su aparición- las tradiciones culinarias.

$8 \quad$ Desarrollada en el marco de una tesis titulada Entre des-ubicamiento y aprendizajes: expresiones de identidades chilenas en adolescentes que conviven con pares inmigrantes en el espacio escolar, para optar al grado de Magíster en Sociología en la Pontifica Universidad Católica de Chile.

9 Somos partidarios de avanzar hacia un lenguaje inclusivo, pero mientras este se establece como norma en publicaciones académicas, en el presente artículo, y desde este punto en adelante, hemos optado por usar exclusivamente el plural en masculino

10 En dichos dispositivos se aplicaron técnicas acordes a la edad, conjugando preguntas semiestructuradas con dinámicas más interactivas.

11 El análisis de los datos cualitativos siguió lineamientos de la Teoría Fundamentada (Charmaz, 2006), utilizándose un enfoque emergente por medio de la búsqueda de tipos de discursos emanados de la lectura de los datos disponibles, más que de un marco anterior cerrado, con el fin de comprender de mejor manera cómo dichos actores viven cotidianamente el proceso. El análisis se realizó con ayuda del programa NVIVO.

12 Estos tres elementos de distinción entre "nosotros" y "los otros" al interior del espacio escolar se encuentran desarrollados en el artículo de Roessler (2018, p. 63-69).

13 Aunque científicamente se ha comprobado la inexistencia de algo semejante a una raza, la ideología racista sigue operando cotidianamente, lo que se refleja en que el sentido común asume que sí existen diferencias raciales (Thayer et al., 2013, p. 169-170). 
La frontera de "lo chileno", emanada de los discursos de los adolescentes en que nos centraremos, implica una identificación con el territorio, en cuanto espacio demarcado por fronteras nacionales, con el que se tiene una historia de pertenencia. Los estudiantes perciben como chileno a quien nace, tiene ascendencia y se socializa en el espacio que coincide con los límites geográficos en los que el Estado chileno marcaría su soberanía (Connor, 1978), el que está delimitado por características geográficas y por tradiciones asociadas a lo nacional. De esa forma, se elaboran fronteras respecto de quienes no cumplen con estas características. En relación con esta identidad territorializada, la mayoría de los adolescentes señalaron sentirse chilenos por nacer en el territorio de la "nación chilena". Algunos también apuntaron al hecho de poseer ascendencia en el territorio nacional, llegando en ocasiones a instalar un componente biológico como parte de una "esencia nacional", al señalar que se es chileno de "sangre" o "genes".

También se relevaron discursos de identificación nacional por criarse o socializarse en el territorio nacional, el que, según su percepción, posee características geográficas propias e irrepetibles, como también tradiciones que tendrían el poder simbólico para representar lo que consideran como "cultura chilena" (Even-Zohar, 2007). Esto emergió tanto al mostrarles fotos de paisajes como al preguntarles "qué se les venía a la cabeza" cuando les decían "Chile" o "chilenos".

En concordancia con su residencia en la capital del país, al hablar de Chile se produjo entre los adolescentes una identificación con paisajes urbanos cotidianos:

“Como que uno dice 'Chile' y es como edificios, altiro [de inmediato], porque están acostumbrados todos a ver edificios, edificios” [E1_Hombre, Santiago].

Pero también inciden en la construcción del imaginario del territorio chileno lo que ven en los medios masivos de comunicación, en fotos y vídeos, en algunas salidas de vacaciones, y lo que se enseña de geografía en la escuela. En relación a la geografía particular del país, predominan discursos sobre "la playa" de la quinta región ${ }^{14}$, los paisajes con mucha vegetación en el sur, y el desierto en el norte. Pero lo que prima en los discursos, como elemento de identificación con todo el territorio (y tiempo), es un imaginario sobre la presencia de la cordillera y del mar como una constante de la geografía chilena. Cordillera y mar marcarían los límites nacionales, y la cordillera sería además lo que separa a Chile de sus países vecinos. El mar, por su parte, se torna importante sobre todo en la relación con los migrantes de Bolivia y Perú, países con los cuales Chile ha tenido históricamente tensiones, incluyendo conflictos relacionados con el territorio marítimo.

Yo el año pasado tenía un compañero que era boliviano y que siempre lo molestaban, como no tenía mar, pa' los partidos también, cuando perdieron, lo webeaban mucho, lo leseaban ${ }^{15}$ po' [FG_Hombre, Quinta Normal].

14 La división político-administrativa de Chile se compone de 15 regiones. La quinta región, o Región de Valparaíso, se encuentra en el centro del país, en el límite norte de la Región Metropolitana, en la que se localiza Santiago, la capital. En la quinta región se ubican los balnearios más asequibles, en términos de distancia y económicos, para la mayor parte de la población metropolitana.

15 "Webear" (un neologismo con guiños al mundo web, que tiene su origen en la palabra "huevear") y "lesear" son chilenismos que básicamente tienen como significado molestar a otro con relación a un tema particular. 
De este modo, los estudiantes van aprendiendo y (re)haciendo lo nacional con el criterio de una pertenencia espacial ligada a ciertos elementos específicos del territorio, algo que Thayer et al. (2013) llaman "geo-identidad", es decir, el rol significativo que la sociedad chilena confiere a la condición geográfica del país como influencia sobre la conformación de una singularidad nacional: la de "país isla" (Thayer et al., 2013), aislamiento que supuestamente estaría determinado por "fronteras naturales" que separan/ protegen del resto del mundo y su influencia: desierto, cordillera y mar, "geosímbolos fronterizos" representados por hitos de la naturaleza que materializan esta representación mental del territorio nacional (González, 2009).

La fuerza que adquiere en Chile la imagen de la frontera, en su acepción acotada a lo territorial, y anclada en estos elementos, explica la relevancia que los estudiantes chilenos le confieren a esa dimensión en estos discursos que actúan como mecanismos de fronterización. Como explica González, "[e]n todo Chile la frontera es un fenómeno que pertenece al imaginario cotidiano por lo angosto que es nuestro territorio y lo imponente que es la cordillera de los Andes" (2009, p. 29), de modo que, además de demarcador territorial, actúa también como demarcador psicosocial.

Ahora bien, debido a su significativa aparición en las narrativas de los estudiantes, nos enfocaremos a continuación, en la comida, que en sus discursos se transforma en lo que, en su investigación sobre la comida tradicional, Giacoman (2015) ha denominado como una patrimonialización orientada a lo nacional. En efecto, de acuerdo a los adolescentes, en el territorio nacional una de las "tradiciones nacionales" destacadas es la comida chilena. Los estudiantes se refirieron tanto a la alimentación cotidiana como a la comida de momentos particulares del año, tales como las fiestas patrias.

Lo que hay en Chile, como la empanada, las ensaladas, las maravillas que tiene, los bailes, la Isla de Pascua [E4_Mujer, Santiago].

- ¿Qué se te viene a la mente cuando te preguntan qué es ser chileno?

- Eeeh... no sé, así como la cultura, la comida tradicional. (...) Como la cazuela, cosas que no se hacen en otros países (...) también he investigado si en otros países hay otras comidas como las de nosotros [E3_Hombre, Quinta Normal].

En el contacto con estudiantes migrantes surge un aprendizaje de lo que serían comidas patrimonializadas de otros países, específicamente de los países de origen de sus compañeros y compañeras. Serían comidas que representan simbólicamente otras identidades, arraigadas a otras naciones (Prats, 1997), y que los estudiantes chilenos, de acuerdo a sus propios relatos, han observado a partir de tres fuentes principales: por medio de lo que les cuentan sus pares migrantes acerca de qué comían en sus países de origen (y que hoy extrañarían); por las fiestas multiculturales que se organizan en las escuelas, cuando las familias migrantes están encargadas de llevar alimentos "tradicionales" de sus países de origen (y en las que ahondaremos más adelante); y finalmente, al haber estado de visita en el hogar o con familia de su(s) amigo(s) extranjeros(s), en el caso de aquellos que tienen vínculos más estrechos con sus pares migrantes. De ese modo surgen sus relatos sobre estas "otras comidas" asociadas a "otras naciones", como la arepa venezolana, y el ceviche y el cuy peruano, entre otros.

En los encuentros con estas otras comidas, los estudiantes van aprendiendo que existen ciertos "límites culturales" -alimentarios en este caso- que diferencian qué se come en sus 
países de origen y en Chile no (y viceversa). Los ejemplos que proveen se refieren tanto a decisiones alimentarias (qué se come y qué no) -que identifican como diferentes a las de los chilenos-como a los sabores de las preparaciones:

Yo no he comido, pero mi amigo boliviano que una vez me dijo que allá en Bolivia se comían tortugas, y encuentran raro que nosotros comamos caballo [FG_Hombre, Santiago].

... mi amigo venezolano trae unas arepas, para compartir colación. Son malas eso sí, son como un pan con queso blanco adentro. No tiene sabor, es como mote [E3_ Hombre, Santiago].

... como que me van mostrando 'mira, esto es de Bolivia', y la mamá me muestra la comida, cómo la hace. (...) cuando voy a su casa es como pura comida... (...) Como arroz, pero el arroz más jugoso, como tiene como más agua y quedan más ricos y con huevo, con huevo, pero el huevo no sé cómo lo hacen es que les queda... Les queda rico [E1_Hombre, Santiago].

En definitiva, hemos visto que el nacimiento, los genes, el mar, la cordillera y el vínculo entre sabores y territorio son elementos propios del espacio que los estudiantes asocian a Chile, y que distinguen a los chilenos de las personas de "otros países", y que por tanto tienen una historia de pertenencia con "otros territorios". Con esto, señalan una frontera cotidiana que es muy difícil de eliminar, puesto que el migrante estaría siempre, de manera casi congénita, en una situación liminal, de desterritorialización, por no tener una historia de pertenencia con el espacio territorial chileno.

En este juego de contrastes, se va aprehendiendo (o encarnando, a modo de habitus) el poder simbólico que tendrían estos elementos considerados como propios de la cultura nacional para representar una identidad social, lo que explica en buena medida la importancia que adquiere la preparación de "platos típicos" de los países de origen de los estudiantes migrantes como una de las formas que las escuelas han encontrado para "integrarlos" a la dinámica institucional, a través de las fiestas multiculturales. Este es uno de los temas que se abordarán en el siguiente apartado.

\section{REIFICAR LA NACIÓN PARA ¿INCORPORAR? LO DIVERSO: PRÁCTICAS ESCOLARES DE INTEGRACIÓN/FRONTERIZACIÓN}

Como hemos señalado, en los últimos años ciertas escuelas municipales de algunas comunas del país han experimentado un incremento muy notable del número de estudiantes migrantes en sus matrículas, lo que en muchos casos ha sucedido en períodos muy cortos de tiempo. Se trata mayoritariamente de migrantes de origen latinoamericano, cuyos países de procedencia se han ido diversificando (Perú, Colombia, Venezuela, Haití, República Dominicana, Bolivia, Ecuador, Argentina, entre otros). De todos modos, es importante volver a enfatizar, para alejar los cómodos y útiles fantasmas de colapso de los servicios públicos que se ligan deliberadamente a la llegada de migrantes, que esta llegada ha permitido revitalizar la matrícula de escuelas públicas que, antes de eso, corrían el riesgo de ser cerradas (Poblete y Galaz, 2007).

Esta llegada significativa y, en varios casos, repentina, ha confrontado a las escuelas con la necesidad de generar respuestas frente a los desafíos que esta diversidad ha implicado para 
una institución que, como hemos dicho previamente, ha sido una de las usinas principales de fabricación del Estado-nación. Una de las primeras y más comunes acciones que se han generado desde aquellas instituciones educativas preocupadas por dar esas respuestas ha sido la emergencia de ciertas prácticas que han apuntado a visibilizar esta presencia, darle un lugar en la dinámica institucional, y sensibilizar a la comunidad educativa frente a esta nueva realidad. En esa línea, muchas de estas escuelas han empezado a incorporar las banderas de los países de origen de los estudiantes migrantes al paisaje escolar, junto con la presencia ya establecida y significativa de la bandera chilena; a cantar los himnos de estos países en algunos actos, como el que se realiza cada lunes en las escuelas públicas para iniciar la semana de estudio; a incorporar sus "bailes y trajes típicos" en actos y otro tipo de actividades, a recordar algunas fiestas patrias de los países de origen de los alumnos extranjeros, e incluso a transformar el perfil de las celebraciones más relevantes del calendario escolar chileno, como lo son las fiestas patrias "propias". Esta transformación ha apuntado a crear celebraciones que den cabida a la presencia de esas otras patrias que han llegado a la escuela, con fiestas que muchos de estos establecimientos han denominado "multiculturales", y que suelen poner en escena esos otros bailes nacionales y trajes típicos, además de disponer estands para la venta de los "platos típicos" de cada país.

No pretendemos desconocer el valor que han tenido estas actividades, que como sostenían Poblete y Galaz (2007) cuando estas prácticas empezaban a ser relevadas desde la investigación en el ámbito nacional, "tienen un sentido inédito en los centros educativos del país y desafían los más tradicionales discursos en torno a la constitución de lo que se considera como ser nacional, el amor a la patria y la defensa de valores fuertemente arraigados en esta sociedad" (2007, p. 13), y que efectivamente han avanzado, aunque sea tibiamente, en la sensibilización sobre la importancia de ver y respetar esta diversidad. Sin embargo, nos parece que es necesario complejizar el análisis respecto de las formas de abordaje de estas presencias en las escuelas, y sopesar las implicaciones que puedan tener. Respecto a esto, el objetivo de este apartado es reflexionar sobre el modo en que estas prácticas de las comunidades educativas están operando como parte relevante de los procesos de fronterización del espacio escolar que venimos describiendo, en la medida que, al centrar las estrategias de incorporación, integración o inclusión de esta diversidad migratoria en la idea de nación, homologando nación con cultura, terminan reificando las fronteras construidas a partir de la articulación entre la matriz colonial y la estado-nacional.

El material empírico que está en la base de este análisis se relevó a través de una investigación ${ }^{16}$ de carácter cualitativo, con elementos de investigación-acción, desarrollada en cinco escuelas de tres comunas de la Región Metropolitana-Independencia, Quilicura y Recoleta-, caracterizadas por una significativa presencia de estudiantes migrantes (de $12,4 \%$ a $46,4 \%$ sobre el total de la matrícula). El levantamiento de datos, que se realizó en 2017, consideró principalmente la realización de entrevistas a actores clave (directivos de departamentos municipales de educación, directores/as de escuelas, jefes de unidades técnico-pedagógicas y encargados de convivencia) y la implementación de talleres con

Se trata del estudio "Construyendo escuelas interculturales: elaboración participativa de una hoja de ruta para asistentes de la educación, profesores y directivos", financiado por el Ministerio de Educación de Chile mediante el Fondo de Investigación y Desarrollo en Educación (FX11622, 2016). Este estudio fue dirigido por Carolina Stefoni, y participaron en él, además de las autoras de este artículo, Javier Corvalán, Tatiana Aguirre, Marcela Tapia y Nanette Liberona. Las opiniones que se presentan en esta publicación, así como los análisis e interpretaciones, son de exclusiva responsabilidad de los autores y no reflejan necesariamente la opinión del MINEDUC. 
docentes y asistentes de la educación ${ }^{17}$. En el análisis que proponemos en este artículo, el foco está puesto en las prácticas relevadas a partir de esas entrevistas y talleres, que representan, según el marco que plantemos inicialmente, formas concretas en que la nación es actuada en la cotidianeidad institucional. En un primer sub-apartado nos ocuparemos específicamente de las fiestas multiculturales, y en el siguiente, de lo que hemos llamado una esencialización Estado-nacionalizante de la cultura que está en la base de muchas de las prácticas descritas previamente.

\subsection{LA PARADOJA DE UNA FIESTA MULTICULTURAL QUE CELEBRA "LA CULTURA NACIONAL"}

A nuestro juicio, existen al menos tres razones por las cuales es relevante analizar en profundidad lo que estas fiestas, descritas al inicio de este apartado, contienen. En primer lugar, dichas celebraciones suelen crear categorías -por ejemplo "los chilenos", "los peruanos", "los colombianos" -que quizás, en la cotidianeidad de la escuela, no son realmente relevantes, y que incluso pueden llegar a producir incomodidad a los alumnos extranjeros. Posiblemente, un niño que ha migrado desde Perú ha comenzado a sentirse un poco chileno además de peruano -iniciando un proceso bastante descrito por la literatura, de conformación de identidades híbridas (Sayad, 2010; Bhabha, 1994)-, pero la celebración multicultural lo "obliga" a identificarse con un Estado-nación representando a un peruano, bailando una "danza peruana", saberse el himno de ese país y traer algo de "su" gastronomía típica. A partir de esas demandas, las niñas y niños son interpelados a identificarse con su país de origen, y con lo que se entiende como la cultura de ese país, es decir, una "cultura nacional". Se desconoce de este modo, como argumenta Eduardo Domenech a partir de un trabajo etnográfico con niños bolivianos en escuelas argentinas, que "esta visión contrastante y dualista de las culturas, que presupone la existencia de diferencias culturales de carácter etnonacionales, coloca a los alumnos/as entre una 'irremediable opción' entre la cultura de origen y la cultura de destino, enajenándolos de 'sus experiencias polivalentes donde se conjugan múltiples referentes culturales y múltiples conflictos, en una construcción irreductiblemente personal de la identidad"” (Domenech, 2014, p. 7).

Al exigir a los estudiantes actuar como embajadores de sus países ${ }^{18}$ (Sharan, 2010), o imponerles una lealtad nacional hacia su país de origen (lo que se vuelve aún más paradójico en el caso de los niños nacidos en Chile, pero de padres extranjeros), se desconoce su derecho a la construcción de su identidad por fuera de esa pertenencia a un Estado-nación, o en un vínculo no exclusivo con él. A esto se suma que, en América Latina, existen una serie de casos en que los pueblos indígenas tienen relaciones conflictivas con los Estados que actualmente administran los territorios en que dichos pueblos han vivido ancestralmente, por lo que también podría darse la situación en la que la adscripción de un niño migrante a un pueblo indígena o a una etnia sea más fuerte y relevante que la

Se realizaron 21 entrevistas a miembros de las directivas de los departamentos de educación municipal, directores/as, jefes/ as de UTP y encargados de convivencia, además de 9 talleres, de los que participaron 191 asistentes en total. El corpus textual resultante de este trabajo de campo (trascripciones de entrevistas y registros etnográficos de talleres) se sistematizó utilizando el programa de análisis cualitativo de datos Atlas.ti.

18 La autora Yael Sharan, una de las precursoras del movimiento del aprendizaje cooperativo, plantea que "as much as teachers need to learn about the general characteristics of different cultures it is helpful to keep in mind that children don't come to school as official ambassadors of their countries of origin. We need to remember that every individual student is not an automatic product of culture, but one who actively interprets it in his or her own way" (Sharan, 2010, p. 8). 
identificación con la nacionalidad que su pasaporte o documento de identidad indica. Tiene algo de paradójico plantear que se celebra la multiculturalidad -es decir, la coexistencia de múltiples culturas, lo que por definición alude a un fenómeno marcado por la diversidad, complejo y dinámico-y, sin embargo, terminar celebrando a las naciones y nacionalidades -entendiéndolas, además, de una manera más estática y monolítica que dinámica e híbrida-. Posiblemente, un nombre más preciso para esta práctica sería el de "celebración de las naciones latinoamericanas y caribeñas".

En segundo lugar, las celebraciones multiculturales se quedan solo en lo que típicamente se considera como parte del folclore nacional, como los bailes, la música, la vestimenta y la comida. Pero la exhibición de estos aspectos no contribuye a tematizar otros más profundos, que son los que realmente inciden en la convivencia y el buen trato entre los estudiantes. Ni las salas de clases ni los patios de los colegios son espacios ajenos a las relaciones de poder que se dan al interior de las sociedades, y en América Latina estas relaciones se han configurado en gran parte, como señalamos al comienzo, en el seno de una matriz colonial, a lo que se sumó posteriormente la doctrina nacionalista. Sin embargo, las celebraciones multiculturales guardan silencio sobre ese hecho, no tematizan las jerarquías raciales y étnicas a partir de las cuales se erigieron esos Estados-nación que se celebran en tanto culturas nacionales. Es decir, en el encuentro de personas de nacionalidades diferentes se producen asimetrías o jerarquizaciones atravesadas por esas desigualdades étnicas y racializadas que devienen de la colonialidad del poder (Quijano, 2000) que ha producido y reproducido a las sociedades latinoamericanas. Si esto no se visibiliza y cuestiona, es poco lo que estas fiestas pueden hacer por la convivencia escolar.

En tercer lugar, las celebraciones multiculturales ocurren no dentro, sino fuera de la sala de clases. Esta sala es el lugar cotidiano de la enseñanza, mientras que el patio u otros espacios externos a ella son el lugar de lo no-habitual (en términos de escolarización). Simbólicamente, mediante las celebraciones multiculturales, se está dando a entender a estudiantes y apoderados que la celebración de la diversidad corresponde al ámbito de lo extraordinario, porque además de ocurrir fuera de la sala, solo se celebra una o dos veces al año. Volviendo a lo planteado por Fox y Miller-Idriss (2008) acerca de la importancia de investigar "cuándo" es la nación, esto equivaldría a decir que la nación (chilena) es todos los días, excepto el día del año en que se realiza la celebración multicultural -y las otras naciones "son" solo el día de la celebración multicultural-. Debido a que la fiesta es el momento de lo excepcional, ese día se presenta a las otras naciones en igualdad de condiciones con la nación chilena, pero durante todos los otros días del año, este afán igualador se pasa por alto. Por lo demás, esas otras naciones se presentan ese día como una unidad homogénea y tipificada, que desconoce la diversidad interior de cada Estado-nación.

Junto con ello, este análisis muestra que, a pesar de la riqueza y la complejidad del concepto de cultura, la materialización de la idea de multiculturalidad que representan estas fiestas escolares reduce la idea de cultura (la propia y la de los estudiantes migrantes) a un sinónimo de la nación, homologación que está estrechamente ligada, como decíamos, al rol protagónico que ha jugado la escuela en y para la construcción del Estado-nación y para el nacionalismo chileno (Cid, 2012), que estaría en la base del hecho que, aparentemente, los actores institucionales de los establecimientos educativos (profesores, directores y otros miembros de los equipos directivos) sienten que su foco exclusivo en la nación chilena y su historia es interpelado por la presencia de los alumnos de otras nacionalidades en sus escuelas (Riedemann, 2017, pp. 111-118). La visibilización de las otras naciones y sus 
símbolos puede ser leída, entonces, como un intento de ofrecer un trato igualitario respecto de la valoración de la nación. Pero esta homologación de cultura con nación, que lleva al énfasis en lo nacional (propio y ajeno) en el intento de diversificar las celebraciones patrias, termina reificando las fronteras nacionales en el espacio escolar, y reproduciendo esas divisiones que supuestamente pretende eliminar. Las consecuencias de esto requerirían un estudio específico, de largo plazo; sin embargo, es posible hipotetizar que no constituyen una respuesta apropiada si lo que se busca es lograr un encuentro real, equitativo y transformador de las culturas presentes en la escuela.

\subsection{LA CULTURA COMO NACIÓN, UNA CONFUSIÓN "ESENCIAL"}

Los resultados de la investigación a la que nos referimos en este apartado permitieron observar entonces una operación de homologación de culturas con naciones en varias prácticas desarrolladas por las escuelas, que hemos ido describiendo hasta aquí. Los fragmentos que siguen, de entrevistas y observaciones registradas durante los talleres efectuados en el trabajo de campo, exponen en primer lugar ideas y razonamientos de los propios actores que están detrás de estas actividades y, en segundo lugar, se refieren a algunas de las tensiones que estas innovaciones han producido.

Por cierto, de lo que se trata es de valorar y entender la diversidad presente y esto hasta ahora se hace más bien a través de un enfoque multicultural, por ejemplo, ahora en la escuela se compraron banderas de todos los países presentes en la escuela y están presentes en todos los actos cívicos, además se realiza una feria gastronómica todos los 12 de octubre (entrevista a encargado/a de convivencia, Independencia).

- Aquí de lo que se trata es de instalar una interculturalidad, esa perspectiva, establecer puentes, tratar de difundir las distintas culturas que existen. No se puede pretender que el sello de la nacionalidad esté de alguna manera sobre los sellos de los niños migrantes. Al revés, tenemos que incorporar esa perspectiva y esa cultura distintas para enriquecer nuestra cultura y para que ellos se enriquezcan de lo que tenemos como idiosincrasia.

- ¿Qué significaría que el sello de la nacionalidad estuviera por encima del sello propio los niños?

- Que el día nacional haitiano yo no me acordara de ellos, yo los tengo que hacer sentir que ellos tienen una raíz y no la pueden olvidar (entrevista a director/a, Quilicura).

En este contexto, que explica esta equiparación incuestionada entre cultura y nación que se realiza desde la escuela, se asume que la forma de dar espacio a las otras culturas que traen los estudiantes migrantes es incorporando los signos y símbolos de esos otros Estados-nación. Los siguientes fragmentos de registros etnográficos de dos talleres son muy decidores de este argumento, justamente porque manifiestan la preocupación por no haberlo logrado, en el primer caso, o por las implicancias de hacerlo, en términos de la "identidad nacional", en el segundo:

Otro profesor, que había vivido como migrante en Suecia, dice que los niños migrantes (en Chile) tienen una identidad nacional débil que debería reforzarse. Comenta que en algún momento se habló de cantar cada lunes los himnos nacionales de los países que 
Estudios Pedagógicos XLV, N $^{\circ}$ 3: 313-331, 2019

RE-PRODUCCIÓN DE FRONTERAS EN EL ESPACIO ESCOLAR. DISCURSOS Y PRÁCTICAS DE DISTINCIÓN NACIONAL(ISTA) EN ESCUELAS CON ALUMNADO MIGRANTE EN LA REGIÓN METROPOLITANA DE CHILE

tienen presencia en la escuela, pero finalmente no se puso en práctica (Observación, taller con profesores y asistentes de la educación, Recoleta).

A raíz de la Fiesta de la Multiculturalidad (que sustituyó la antigua peña para septiembre), algunos apoderados chilenos han mostrado molestia debido a la 'pérdida de los valores propios e identidad chilena' por darle cabida a los inmigrantes. Las educadoras han respondido que los migrantes ya están y necesitan un espacio también (Observación, taller con profesores y asistentes de la educación, Independencia).

Como hemos adelantado, proponemos que esta homologación de cultura y nación que se realiza mediante las prácticas reseñadas (banderas, himnos, bailes, trajes y comidas típicas, fiestas "multiculturales") podría entenderse como un mecanismo de esencialización Estado-nacionalizante de las culturas. Este mecanismo, según lo observamos, tiene dos componentes principales: por una parte, está la operación de esencialización, consistente básicamente en asociar la cultura a ciertos objetos y prácticas que reducen los procesos culturales a cristalizaciones inmutables de una identidad que se asume como única y homogénea; una esencia que constituiría el núcleo definitorio de cada cultura. Como se ha relevado en la literatura latinoamericana referida a la interculturalidad en clave indígena, este parece ser un mecanismo bastante común en escenarios educativos que se enfrentan a la diversidad cultural: "La mayoría de los actores educativos que aún no tienen experiencia en contextos interculturales optan por 'etnificar' las diferencias culturales, presentándolas como 'esencias' étnicas de un determinado grupo de estudiantes y reificando sus respectivas características culturales" (Guilherme y Dietz, 2014, p. 24). En los casos de los que nos estamos ocupando, estas esencias no son étnicas sino nacionales (o étnico-nacionales, como hemos explicado), aunque algunos actores hacer confluir estos conceptos:

Nosotros tenemos un encuentro latinoamericano que se realiza una vez al año. Este año se realizará el tercero y ahí también se destaca la etnia chilena versus la etnia de otros países, Colombia, Perú, Haití, sus bailes y sus costumbres su música se destaca (entrevista a director/a, Independencia).

El otro componente de este mecanismo es la vinculación de esa "esencia cultural" con un Estado-nación, del que comidas típicas, danzas, trajes, símbolos patrios como banderas, himnos y días nacionales serían expresiones metonímicas. Es decir, se da por sentado el carácter monocultural del Estado-nación, tanto el de los niños y niñas migrantes como el de los chilenos. Pero, si bien es cierto que en los Estados-nación puede verificarse la existencia de configuraciones culturales (Grimson, 2012) nacionales, también es un hecho que estas conviven, muchas veces en tensión, o en abierta confrontación, con otras configuraciones culturales. Por lo tanto, a través de este mecanismo de esencialización Estado-nacionalizante de la cultura, se oculta, aunque no sea de manera intencional, el nudo traumático constitutivo (Cuevas, 2014) de esas identificaciones culturales, tanto del Estado-nación receptor como de los de origen de los estudiantes. Desde el horizonte de la interculturalidad crítica, que es el que consideramos más idóneo para abordar este proceso social, eso implica desconocer la colonialidad del poder que está detrás de la construcción de los Estados-nación, e invisibilizar la heterogeneidad que estuvo en la base de la institución de esa cultura hegemónica. 


\section{REFLEXIONES FINALES: DES-NACIONALIZAR, DES-COLONIZAR, INTERCULTURALIZAR}

Hemos revisado y analizado, a lo largo de este artículo, discursos y prácticas de diversos actores de escuelas públicas de la Región Metropolitana que han estado recibiendo a estudiantes migrantes en los últimos años, procurando mostrar diversos mecanismos de fronterización y de lo que hemos denominado como una esencialización Estadonacionalizante de la cultura que está en la base de estos decires y haceres, y que opera en el espacio escolar produciendo y re-produciendo fronteras nacionales entre los miembros de las comunidades educativas. Nuestro análisis estuvo centrado en materializaciones de los modos en que el Estado construye legitimidades y regímenes de adscripción. Por lo tanto, debe señalarse la necesidad de avanzar en investigaciones que releven los modos en que los actores escolares renegocian, resisten, desafían y transforman esas legitimidades y adscripciones, procesos que no fueron el foco de este análisis. Específicamente, sería importante explorar cómo están resistiendo los estudiantes migrantes estos modos de adscribir sus procesos de construcción identitaria a sus Estados-nación exclusivamente.

Señalamos también en este artículo que, aunque en principio consiguen justamente lo contrario, las prácticas de las que nos ocupamos han surgido con el propósito de incluir a los estudiantes migrantes, y a sus familias, en las escuelas y su cotidianeidad. Cabe preguntarse, entonces, cuáles serían los caminos más apropiados para lograr esos objetivos, entendiendo que no lo son estas acciones centradas en la idea de nación, homologada a cultura.

Como hemos afirmado en este mismo texto, y en otros trabajos previos (por ejemplo, Stefoni et al., 2016; PRIEM y FUSUPO, 2016), entendemos que la educación intercultural con enfoque crítico parece ser la herramienta más idónea, en la medida que no se limita a buscar la generación de espacios de encuentro y comunicación entre diferentes culturas (es decir, personas, prácticas, saberes, valores y tradiciones), sino que problematiza las estructuras sociales que han llevado a que esas diferencias culturales se transformen en desigualdad (Walsh, 2011).

En relación específica con los discursos y prácticas que hemos analizado en este artículo, un abordaje educativo desde la interculturalidad crítica permitiría contrarrestar estos procesos de fronterización sustentados en mecanismos de esencialización Estadonacionalizantes porque:

- En la medida que pone el foco en un horizonte normativo respecto de cómo debiese ser el encuentro de las culturas de los estudiantes y sus familias, descentra la mirada de la nación y lo nacional, es decir, des-nacionaliza el abordaje.

- En tanto que busca visibilizar las relaciones de poder que atraviesan las configuraciones culturales que se encuentran en las escuelas, permite pensar las culturas en sentido denso, más allá de lo que se entienden como sus manifestaciones más típicas (bailes, comidas, símbolos, etc.), alejándonos de ese modo de miradas "culturalistas".

- Tiene un horizonte de cambio, en el sentido que propone "la transformación de las estructuras, instituciones y relaciones sociales, y la construcción de condiciones de estar, ser, pensar, conocer, aprender, sentir y vivir distintas" (Walsh, 2011, p. 102).

- Entiende que, en América Latina, no es posible apuntar a esa transformación si no se problematiza la estructura colonial y colonialista que está en la base de estas estructuras, es decir, entiende que se debe des-colonizar el abordaje. 
Estudios Pedagógicos XLV, N $^{\circ}$ 3: 313-331, 2019 RE-PRODUCCIÓN DE FRONTERAS EN EL ESPACIO ESCOLAR. DISCURSOS Y PRÁCTICAS DE DISTINCIÓN NACIONAL(ISTA) EN ESCUELAS CON ALUMNADO MIGRANTE EN LA REGIÓN METROPOLITANA DE CHILE

Pero este enfoque, según la propuesta de Catherine Walsh, no es un modelo existente a implementar, es en cambio un proyecto por construir, y por eso que, tomando sus palabras, hablamos de interculturalizar las relaciones sociales en la escuela, como "estrategia, acción y proceso permanente de relación y negociación... en condiciones que propici[e]n el respeto, legitimidad, simetría, equidad e igualdad" (2011, p. 103).

\section{REFERENCIAS BIBLIOGRÁFICAS}

Bengoa, J. (2003). Erosión y transformación de las identidades en Chile. Indiana, (19-20), (2002/2003), 37-57.

Bertoni, L. A. (1992). Construir la nacionalidad: héroes, estatuas y fiestas patrias, 1887-1891. Boletín del Instituto de Historia Argentina y Americana "Dr. E. Ravignani”, tercera serie, (5), 77-111.

Bhabha, H. (1994). The location of culture. London: Routledge.

Bourdieu, P. \& Passeron, J. C. (1996). La reproducción. Elementos para una teoría del sistema de enseñanza (2a ed.). Mexico DF: Editorial Laia S.A.

Charmaz, K. (2006). Constructing grounded theory: A practical guide through qualitative analysis. Recuperado de http://www.sxf.uevora.pt/wpcontent/uploads/2013/03/Charmaz_2006.pdf.

Chernilo, D. (2006). Social theory's methodological nationalism: Myth and reality. European Journal of Social Theory, 9(1), 5-22.

Cid, G. (2012). La nación bajo examen. La historiografía sobre el nacionalismo y la identidad nacional en el siglo XIX chileno. Polis, Revista de la Universidad Bolivariana, 11(32), 329-350.

Comunidad de Historia Mapuche (2015). Violencias coloniales en Wajmapu. Temuco: Ediciones Comunidad de Historia Mapuche.

Connor, W. (1978). A nation is a nation, is a state, is an ethnic group, is a... Ethnic and Racial Studies, $1(4), 379-388$.

Cuevas, H. (2014). Discurso militar e identidad nacional chilena. Polis. Revista Latinoamericana, $13(38), 467-498$.

Díaz, T. y Druker, S. (2007). La democratización del espacio escolar: una construcción en y para la diversidad. Estudios Pedagógicos, 23(1), 63-77.

Diez, M. L. (2004). Reflexiones en torno a la interculturalidad. Cuadernos de Antropología Social, 147(19), 191-213.

Domenech, E. (2003). El multiculturalismo en Argentina: ausencias, ambigüedades y acusaciones", Estudios: Centro d Estudios Avanzados, (14), 33-47.

Domenech, E. (2014). "Bolivianos" en la "escuela argentina": representaciones acerca de los hijos de inmigrantes bolivianos en una escuela de la periferia urbana. Revista Interdisciplinar da Mobilidade Humana, XXII(42), 171-188.

Donoso, A. (2008). Educación y nación al sur de la frontera. Organizaciones mapuche en el umbral de nuestra contemporaneidad, 1880-1930. Santiago: Pehuén.

Egaña, M. (2000). La educación primaria popular en el siglo XIX en Chile: Una práctica de política estatal. Colección Sociedad y Cultura. Santiago de Chile: Dibam, Lom.

Even-Zohar, I. (2007). Conflicto Lingüístico e Identidad nacional. Polisistems de Cultura, 1-8.

Faist, T. (2004). The migration-security nexus. International migration and security before and after 9/11. Migration, Citizenship, Ethnos, 103-119.

Fernández, M. (2018). Mapa del estudiantado extranjero en el sistema escolar chileno (2015-2017). Documento de trabajo $\mathrm{N}^{\circ} 12$, Ministerio de Educación, Santiago.

Fox, J. E. \& Miller-Idriss, C. (2008). Everyday nationhood. Ethnicities, 8(4), 536-563.

Giacoman, C. (2015). Reflexiones acerca de las cocinas nacionales como Patrimonio Inmaterial. Observatorio Cultural, 26(1). 
Estudios Pedagógicos XLV, N 3: 313-331, 2019

RE-PRODUCCIÓN DE FRONTERAS EN EL ESPACIO ESCOLAR. DISCURSOS Y PRÁCTICAS DE DISTINCIÓN

NACIONAL(ISTA) EN ESCUELAS CON ALUMNADO MIGRANTE EN LA REGIÓN METROPOLITANA DE CHILE

Giroux, H. (2011). On critical pedagogy. New York: Continuum International Publishing Group.

González, S. (2009). El Norte Grande de Chile y sus dos Triple-Fronteras: Andina (Perú, Bolivia y Chile) y Circumpuneña (Bolivia, Argentina y Chile). Cuadernos Interculturales, 7(13), 27-42.

Grimson, A. (2012). Los límites de la cultura. Crítica de las teorías de la identidad. Buenos Aires: Siglo XXI.

Guilherme, M. y Dietz, G. (2014). Diferencia en la diversidad: perspectivas múltiples de complejidades conceptuales multi, inter y transculturales. Estudios sobre las Culturas Contemporáneas, $X X(40), 13-36$.

Hobsbawm, E. (1990). Nations and nationalism since 1870: Programme, myth, reality. Cambridge: Cambridge University Press.

Poblete, R. y Galaz, C. (2007). La identidad en la encrucijada: migración peruana y educación en el Chile de hoy. EMIGRA Working Papers, (3). Recuperado de www.emigra.org.es.

Prats, L. (1997). Antropología y patrimonio. Barcelona: Ariel.

PRIEM y FUSUPO (Programa Interdisciplinario de Estudios Migratorios y Fundación para la Superación de la Pobreza). (2017). Guía pedagógica para una educación intercultural, antiracisata y con perspectiva de género. Ideas, experiencias y herramientas. Recuperado de: http:// www.superacionpobreza.cl/wp-content/uploads/2017/03/Gu\%C3\%ADa-pedag\%C3\%B3gicapara-una-educaci\%C3\%B3n-intercultural-anti-racista-y-con-perspectiva-de-g\%C3\%A9nero.pdf.

Quijano, A. (2000). Colonialidad del poder y clasificación social. Journal of World-System Research, $X I(2), 342-386$.

Ramírez, J. y Álvarez, S. (2009). “Cruzando fronteras”: una aproximación etnográfica a la migración clandestina ecuatoriana en tránsito hacia Estados Unidos. CONFLUENZE Revista Di Studi Iberoamericani, 1(1), 89-113.

Riedemann, A. (2017). Alumnos migrantes en escuelas chilenas: una mirada a las nuevas desigualdades del sistema educativo, en: Malestar social y desigualdades en Chile. Santiago de Chile: Ediciones Universidad Alberto Hurtado.

Roessler, P. (2018). Pensamiento nacionalista-territorializado y percepción de "des-ubicamiento" del inmigrante: el camino hostil de las construcciones de identidades chilenas en la convivencia escolar. Calidad en la Educación, (49), 50-81.

Rojas Flores, J. (2004). Moral y prácticas cívicas en los niños chilenos, 1880-1950. Santiago: Ariadna Ediciones.

Sayad, A. (2010). La doble ausencia. De las ilusiones del emigrado a los padecimientos del inmigrado. Barcelona: Anthropos Editorial.

Segato, R. (2007). La Nación y sus Otros. Raza, etnicidad y diversidad religiosa en tiempo de Políticas de Identidad. Buenos Aires: Prometeo.

Sharan, Y. (2010). Cooperative Learning: a diversified Pedagogy for diverse Classrooms. Intercultural Education, 21(3), 195-203.

Sistema Información General de Estudiantes, SIGE. (2018). Matrícula por estudiante año 2018. Recuperado de: http://datos.mineduc.cl/ dashboards/19776/descarga-bases-de-datos-dematricula-porestudiante/.

Skey, M. (2009). The national in everyday life: A critical engagement with Michael Billigs thesis of banal nationalism. The Sociological Review, 57(2), 331-346.

Stefoni, C., Guizardi, M. L. y Gonzálvez, H. (2018). La construcción política de la frontera. Entre los discursos nacionalistas y la 'producción' de trabajadores precarios. Polis, Revista Latinoamericana, 17(51), 137-162.

Stefoni, C., Stang, F., y Riedemann, A. (2016). Educación e interculturalidad en Chile: un marco para el análisis. Estudios Internacionales (Santiago), 48(185), 153-182.

Thayer, L. E., Córdova, M. G., y Ávalos, B. (2013). Los límites del reconocimiento: migrantes latinoamericanos en la Región Metropolitana de Santiago de Chile. Perfiles Latinoamericanos, 21(42), 163-191. 
RE-PRODUCCIÓN DE FRONTERAS EN EL ESPACIO ESCOLAR. DISCURSOS Y PRÁCTICAS DE DISTINCIÓN NACIONAL(ISTA) EN ESCUELAS CON ALUMNADO MIGRANTE EN LA REGIÓN METROPOLITANA DE CHILE

Tijoux, M. E. (2013). Niños(as) marcados por la inmigración peruana: estigma, sufrimientos, resistencias. Convergencia, Revista de Ciencias Sociales, 20(61), 83-104.

Tijoux, M. E. y Córdova, M. G. (2015). Racismo en Chile: colonialismo, nacionalismo, capitalismo. Polis, Revista Latinoamericana, (42).

Todorov, T. (2010). La conquista de América. El problema del otro. Madrid: Editorial Siglo XXI.

Vigh, H. (2009). Wayward migration: On imagined futures and technological voids. Ethnos, 74(1), 91-109.

Walsh, C. (2003). Las geopolíticas del conocimiento y colonialidad del poder. Polis. Revista Latinoamericana [En línea], 4. Publicado el 19 octubre 2012, recuperado el 28 febrero 2019. . (2009). Interculturalidad crítica y educación intercultural. En Interculturalidad y Educación Intercultural (pp. 1-12). Recuperado de http://www.saludpublica.uchile.cl/u/download.jsp?docu ment $=110597 \&$ property $=$ attachment $\&$ index $=0 \&$ content $=$ null.

. (2011). Etnoeducación e interculturalidad en perspectiva decolonial, en Centro de Desarrollo Étnico (CEDET). Desde adentro. Etnoeducación e Interculturalidad en el Perú y América Latina. Lima: Bellido Ediciones. . (2012). Interculturalidad y (de)colonialidad: Perspectivas críticas y políticas. Visão Global, Joaçaba, 15(1-2), 61-74.

Wimmer, A. \& Glick Schiller, N. (2002). Methodological nationalism and beyond: nation-state building, migration and the social sciences. Global Networks, 2(4), 301-334. 
